\title{
MATERIALS ISSUES IN
}

\section{MODERN REACTOR SAFETY}

\author{
D.A. Powers \\ Sandia National Laboratories \\ Albuquerque, NM
}

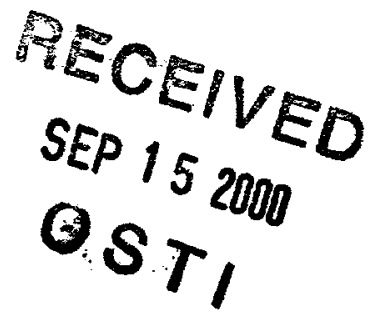

\begin{abstract}
:
Nuclear power currently supplies about $20 \%$ of the nation's electrical power needs. The nuclear power industry is going through evolutions that will lead to greater efficiency and competitiveness. Many changes in the nuclear power industry are limited by materials issues. This paper discusses a representative range of the materials issues that are arising in the industry. Materials issues are associated with prolonged use of reactor fuel, extended operation of power plants and realistic analyses of power plant safety. The issues include questions of fuel stability at high burnups, metallurgical issues of fuel cladding, embrittlement of pressure boundaries, detecting and sizing flaws in steam generators and issues of environmental qualification of reactor control and instrumentation systems. The paper concludes with a discussion of the future of nuclear power and the continuing need for better materials for power plants.
\end{abstract}

\section{INTRODUCTION}

This paper will present an outline of the materials issues that confront the nuclear power industry. The intention is not to present a comprehensive list of the materials issues. Rather, the intention is to provide illustrative examples of issues that represent the range of materials issues that are arising. This range is, indeed, extensive. It includes issues of metallurgy, ceramics, material properties, material processes, data needs and modeling of materials. The paper concludes with a discussion of the future of nuclear power that shows the importance of materials will be no less in the future than it is today. 


\section{DISCLAIMER}

This report was prepared as an account of work sponsored by an agency of the United States Government. Neither the United States Government nor any agency thereof, nor any of their employees, make any warranty, express or implied, or assumes any legal liability or responsibility for the accuracy, completeness, or usefulness of any information, apparatus, product, or process disclosed, or represents that its use would not infringe privately owned rights. Reference herein to any specific commercial product, process, or service by trade name, trademark, manufacturer, or otherwise does not necessarily constitute or imply its endorsement, recommendation, or favoring by the United States Government or any agency thereof. The views and opinions of authors expressed herein do not necessarily state or reflect those of the United States Government or any agency thereof. 


\section{DISCLAIMER}

Portions of this document may be illegible in electronic image products. Images are produced from the best available original document. 


\section{BACKGROUND}

Before delving into the meat of the subject of materials in the nuclear power industry, it is useful to examine the current state of the industry. There are some well-known facts about the nuclear power industry. Nuclear power provides today about $20 \%$ of the nation's electrical energy. In some regions of the country, notably the Northeast, the contribution of nuclear power to the total electrical power supply is much higher. There are about 103 operating power plants. A majority of the power plants are of the pressurized water reactor design, but a significant fraction are boiling water reactors. Altogether, we now have about 3000 reactor-years of operating experience with these plants. There has not been a new nuclear power plant ordered in this country since about 1979 .

All of these facts would lead one to assume that the nuclear power production industry is mature and stable if not stagnant. This is not at all the case. The country is undergoing a change that involves the economic deregulation of power production including power production from nuclear plants. Today, about 60 of the 103 operating plants are operating under a deregulated regime where they price compete to supply electricity to distribution companies. The challenges that this enhanced competition implies are being met by the nuclear power industry. Availabilities of nuclear power plants to produce power have reached an all-time high. By all measures, financial and regulatory, power plants are being operated better and more safely than they ever have been. At least three quarters of the plants are producing power at sustained costs that are well below replacement costs with any alternative technology. As noted by one industry spokesman, utilities may need to build new gas cycle plants to meet increased demand for electricity, but they don't have to do so to replace inefficient nuclear power plants.

Utilities are seeking permission to uprate the operating power of their existing plants. The power uprates granted so far by the U.S. Nuclear Regulatory Commission together amount to the construction of a new $1200 \mathrm{MW}_{\mathrm{e}}$ power plant. Power plants are going to longer fuel cycles to reduce fuel costs and to reduce lost revenues from plant shutdowns for refueling. Today most plants are on an 18-month refueling schedule and many plan to move to a 24-month cycle time. Utilities are seeking to extend their operating licenses from 40 years to 60 years. License extensions have just been granted to the two Calvert Cliffs units and it is anticipated that in the next months license extensions will be granted to the three Oconee units. It is now thought that as many as 80 of the existing plants will ask for license extension. To gain these license extensions, there are requirements for scrupulous examination of the plants aging components.

As these changes in the nuclear power industry have been taking place, there have been changes in the way the plants are regulated for safety. Armed with extensive operating experience with plants and new methods of safety analysis, the U.S. Nuclear Regulatory Commission is evolving its regulations from a deliberately conservative basis to a more realistic foundation based on quantitative information about actual risks plants pose to public health and safety. Among the many implications of this evolution in the regulations is that there are advantages for both safety and plant operations to use more realistic models for understanding 
the behavior of materials in the plants.

Though the details of safety regulation of nuclear power plants are changing, the underlying structure of the safety regulation is still based on defense in depth against the accidental release of radioactive materials from the plants. In practice, defense in depth means providing redundant means to prevent nuclear reactor accidents and multiple barriers against radionuclide releases should accidents occur. The important barriers to radionuclide release are:

- a refractory oxide fuel that tends to retain fission products formed during operation, - a ductile metallic cladding of the fuel to retain fission products that escape the fuel, - a reactor pressure boundary to retain fission products should the cladding rupture, and

- a reactor containment to retain fission products should the pressure boundary fail.

These layers of defense in depth provide a convenient framework for the discussion of many of the materials issues that are arising in the nuclear power industry today. In the next section of this paper, materials issues in each of the barriers will be discussed.

\section{A CROSS-SECTION OF MATERIALS ISSUES}

\section{A. The Reactor Fuel}

Fuel in U.S. nuclear power plants is uranium dioxide enriched to about $3 \%$ in the fissile isotope ${ }^{235} \mathrm{U}$. In the 1960 's and 1970's, industry and the U.S. Nuclear Regulatory Commission expended substantial resources developing this reactor fuel. Eventually, the country had the best fuel technology in the world. Fuels were studied both under normal operating conditions and under postulated accident conditions, such as the conditions that are produced by an accidental insertion of reactivity that could cause a power and temperature excursion in the fuel. Great confidence developed in the capabilities of the fuel. It was thought that fuel behavior could be predicted well based on a rich data base for fuel burnups up to $20 \mathrm{GWd} / \mathrm{t}$ and a sparser data base that went as high as about $33 \mathrm{GWd} / \mathrm{t}$.

But, there are tremendous economic incentives to use fuel to higher burnups. There are also significant social incentives to take fuel to higher burnups. Using fuel to higher burnups means there is less spent fuel to store and to dispose eventually in a geologic repository. So, fuel burnups crept upward. Today, fuel burnups can exceed $55 \mathrm{GWd} / \mathrm{t}$. At these levels, however, there is a change in fuel physics. The change is often termed the "rim" effect since a high porosity rim at the periphery of individual fuel pellets develops at high burnups. The pore regions are filled with gaseous fission products $(\mathrm{Kr}$ and $\mathrm{Xe})$ and fuel becomes susceptible to damage during sudden insertions of reactivity. This susceptibility is shown in Figure 1 which is a plot of fuel behavior during reactivity insertions as a function of fuel burnup [1]. The vertical scale of the plot is the energy increase of the fuel as a result of a reactivity insertion. Solid symbols in the plot denote tests in which the fuel survived the reactivity insertion and open symbols denote fuel that was damaged by the reactivity insertion. 
Clearly, the threshold for fuel damage has fallen significantly as fuel burnups have progressed beyond about $50 \mathrm{GWd} / \mathrm{t}$. The materials issue is whether fuel can found that does not suffer deleterious changes in microstructure at elevated burnup.

\section{B. The Fuel Cladding}

The metallic cladding on reactor fuel in power reactors is zirconium alloyed with a small amount of tin. During normal operations there is a progressive oxidation of the zirconium by water to form zirconium dioxide and hydrogen. Most of the hydrogen produced by the reaction is released to the reactor coolant, but a small fraction of the hydrogen is absorbed into the zirconium alloy. As fuel is used to higher burn ups, the cladding on the fuel is oxidized to thicknesses of up to $100 \mu \mathrm{m}$. Worse, hydrogen dissolved in the cladding migrates to cooler spots such as points where the insulating oxide on the clad has exfoliated or to points in the clad over gaps between fuel pellets. Hydrogen concentrations in the cladding at the cooler spots can be high enough (1000 ppm) that zirconium hydrides precipitate. The cladding becomes embrittled. Embrittlement of the cladding raises questions about whether the cladding will remain intact during hypothesized accidents. Indeed, the U.S. Nuclear Regulatory Commission has undertaken an extensive program to investigate the mechanical properties of cladding subjected to high burnup fuel operations.

Understanding the behavior and properties of cladding taken to high fuel burnups is, of course, a fascinating undertaking because the effects of burnup may depend on so many variables including burnup rate, linear heating rate of the fuel, water chemistry and operational practices. Of more interest is finding cladding that will not be so susceptible to the deleterious effects of high burnup. Russian pressurized water reactors have long used a cladding alloy of zirconium containing a few percent niobium. This alloy does, indeed, seem to perform better under high burnup conditions than do the zirconium-tin alloys. In the USA, alloys of zirconium with tin and niobium are being tried and show some promise. There is still room alloy development because the aspiration is to take fuels to even higher burnups than those envisaged today. Current regulatory limits on fuel burnup are for $62 \mathrm{GWd} / \mathrm{t}$. There is active interest within the power industry in going to burnups of $75 \mathrm{GWd} / \mathrm{t}$ and academic interest in taking the uranium dioxide fuel to over $100 \mathrm{GWd} / \mathrm{t}$. Reducing the oxidation of cladding from nominally $100 \mu \mathrm{m}$ to less than $40 \mu \mathrm{m}$ during burnups to $75 \mathrm{GWd} / \mathrm{t}$ could lead to further power uprates for power plants not to mention additional societal savings in reduced inventories of spent fuel for eventual disposal.

\section{Axial Offset Anomaly}

Other materials issues arise in connection with fuel and higher fuel burnups. Higher fuel enrichments in fissile isotopes are needed to achieve very high burnups. To control the neutronic reactivity of the core when fuel is freshly installed, it is necessary to use higher concentrations of borate and boric acid in the reactor coolant. It has been found that in some cases borates absorb onto the upper regions of the fuel cladding at the higher concentrations. This has the effect of 
distorting the power profile of the core so that there is a higher power profile lower in the core. The effect has become known as the axial offset anomaly. In at least one case, the distortion of the power profile has been sufficient that the plant came into violation of its technical specifications and the operating power had to be reduced.

There is, then, and interest in knowing how to prevent borate adsorption onto the zirconium dioxide surface of fuel cladding. Can it be controlled by water chemistry, coolant additives, or by alterations in the chemistry of the clad or the oxide?

\section{Reactor Vessel Embrittlement}

The reactor pressure boundary is the next line of defense in depth that deserves attention. An important element of this boundary is the reactor vessel itself surrounding the reactor core. The vessel is made of ferritic steel up to $20 \mathrm{~cm}$ thick. It is susceptible to embrittlement as a result of the neutron irradiation that it receives during normal plant operation. The embrittlement is controlled significantly by choices made about the fuel distribution within the reactor core. The embrittlement is monitored by examining the changes in the nil ductility temperature of samples suspended in the reactor coolant near the vessel. It is now believed that all reactor vessels in operating power plants will retain sufficient ductility to be used through the ends of their current licensing periods. Most can even survive through 60 years of operation.

Still, the issue of embrittlement does affect the operation of nuclear power plants. Fairly tight controls are placed on the startup and shutdown of pressurized water reactor to avoid placing extreme thermal stresses on the vessels. There has been concern that activation of the Emergency Core Cooling system could deluge the vessel with cold water and lead to vessel failure by pressurized thermal shock. Conservative analytic procedures have been imposed on the operations of the reactor to avoid this possibility. These procedures have become so conservative that they threaten to interfere in the normal startup and shutdown operations of a plant. There is interest in using more realistic analyses to develop more technically defensible limits to avoid pressurized thermal shock.

The approach being adopted to develop better controls on the plants is based on the combination of probabilistic risk assessment, deterministic thermal hydraulics analyses, and probabilistic fracture mechanics. The analyses to date have shown that the input to the probabilistic fracture mechanics is the controlling feature of the analysis. The issue boils down to predicting the flaw size distribution, flaw density, flaw location and flaw orientation in the reactor vessel steel, especially welds in the steel.

In the past analyses, the so-called Marshall flaw distribution (See Figure 2) developed by expert opinion elicitation has been used for the analyses [2,3]. It was then assumed that all the flaws having this size distribution were located at the vessel surface and extended through the stainless steel cladding on the surface. We now have the benefit of much more data on the flaw size distributions in actual reactor vessel materials. There is interest in developing improved 
versions of the Marshall size distribution (though the distribution may still be the result of expert opinion elicitation) and supplementing this distribution with distributions concerning location and orientation of the flaws. The combined distributions would then be used in revised fracture mechanics analyses as part of a larger effort to establish operating criteria to avoid pressurized thermal shock.

\section{E. Corrosion}

Any time steel is used in water systems, the issues of corrosion arise and the nuclear power industry has had its full share of corrosion issues to confront. On average plants lose 3-5\% of their capacity due to corrosion events. The principal issues of interest are stress corrosion cracking of components in the reactor primary circuit and flow accelerated corrosion in the secondary (steam-producing) systems of the plant. Segregation caused by irradiation can sensitize stainless steel to stress corrosion cracking where otherwise the steel would be considered insensitive.

Stress corrosion cracking is not unique to the nuclear industry by any means. A unique form of stress corrosion cracking dubbed "irradiation assisted stress corrosion cracking" has been identified and is affecting especially the internal components of boiling water reactors.

Flow assisted corrosion is also not unique to the nuclear industry. Control of water chemistry is the first line of defense against this particular variety of corrosion. The second line of defense in the nuclear industry has been to use models based on empirical correlations of past events [4] to identify susceptible locations and to monitor these locations. This has not been infallible against flow assisted corrosion and there is a continuing need for better predictive models for corrosion susceptibility [5].

\section{F. Steam Generator Tubes}

Pressurized water reactors have steam generator tubes that conduct primary coolant through thousands of steam generator tubes. Steam generator tubes have proved to be especially susceptible to corrosion. This is a concern because the tubes are the interfaces between the high and low pressure systems of a plant and constitute parts of both the pressure boundary of the plant and the containment of the plant. Rupture of a steam generator tube is a design-basis accident for a pressurized water reactor. Even so, when it occurs, it can cause the plant to be shutdown for prolonged periods of time.

Corrosion of these tubes was actually well anticipated by both the design and regulations of nuclear power plants. Unfortunately, it was assumed at the time the regulations were developed that the principle corrosion process would involve the wastage of tube walls. It was required that tubes be plugged or removed once corrosion had penetrated through $40 \%$ of the wall thickness. The causes of corrosion that lead to wastage of tube walls have largely been eliminated in nuclear power plants by careful control of the coolant water chemistry. The 
problem faced by plant operators now is stress corrosion cracking of the tubes.

Stress corrosion cracking is, of course, very much different from corrosion that leads to wastage. Still, the requirement that tubes be plugged, removed or replaced when cracks penetrate through $40 \%$ of the wall thickness remains in place and seems to be prudent. The challenge faced by the nuclear industry is that detection of stress corrosion cracks is possible, but sizing these cracks is quite difficult. Consequently, the industry is having to plug or remove steam generator tubes whenever there are indications of the existence of cracks even though the detected cracks may be too small to pose any real threats of tube rupture. This is having a serious impact on plants. Though the generators are manufactured with substantial numbers of "excess" tubes, tube plugging and removal have reached the point in at least one plant that power derating of the plant may be necessary.

There is a need for better methods to both detect and to size crack produced by the stress corrosion mechanism. Better technology is needed to size indications of cracks that can now be detected. Once superior technology is available for sizing cracks, better technology will be needed to predict whether cracks will grow to unacceptable dimensions during future cycles of plant operations.

\section{G. Fatigue and Cable Aging}

As the nuclear industry looks to extending the operating lifetimes of its nuclear power plants it becomes important to consider the aging of plant components. Many of the components are replaced regularly and need not receive special considerations for the purposes of licensing extension. The focus of attention, then, is on those components that are not regularly replaced and may not be easily inspected. The issues of metal fatigue and the aging of electrical cables that are buried or otherwise embedded in structures come to the fore.

The aging of electrical cables has received substantial attention. Of course, with aging the insulation on cable becomes less flexible. It has been found that the electrical insulation on cables becomes more resistant to fire as it ages and greater crosslinking occurs. There are synergistic effects between radiation and temperature on the degradation of cable insulation properties. What is really needed for buried cables is to have techniques for remotely sensing whether the degradation of cable insulation has affected the ability of the cable to perform its intended function and carry its intended current especially under accident conditions.

Fatigue in nuclear components has proved to be an especially interesting area of investigation because the high temperature water environment of the metals seems to accentuate the sensitivity of the metals to thermal cycling. It has been found for carbon steels that fatigue

design curves from the ASME boiler and pressure vessel code are not conservative when:

- dissolved oxygen exceeds $0.05 \mathrm{ppm}$,

- temperatures exceed $150{ }^{\circ} \mathrm{C}$, 
- strain rates are less than $1 \% / \mathrm{s}$, and

- sulfur content of the steel exceeds 0.003 weight $\%$.

\section{H. Environmental Qualification of Digital Electronics}

A nuclear power plant is never a static entity. It is always being upgraded and improved. One area where upgrading is becoming essential for the nuclear power industry is the area of instrumentation and control. There are, of course, safety and economic incentives for the nuclear industry to move from the analog systems for instrumentation and control to software-based digital systems. Such systems have the potential of offering more detailed information together with self-calibration and error correction. Plants could be operated closer to optimal conditions and indications of upsets could be detected more easily. The question comes about the environmental qualification of digital systems in nuclear power plants.

Environmental qualification of nuclear power plant systems considers both the environments of normal operations and the environments of accidents. There are many things that could potential affect digital systems including temperature, humidity and radiofrequency interferences. An issue that is some interest is how smoke, especially from incidental fires that otherwise do no significant damage to the plant, might affect the performance of digital systems. Exploratory research has shown that some types of digital systems are susceptible to short term damage from smoke while other types are largely immune [6]. An issue of greater interest is how the corrosive properties of smoke may affect digital systems over a longer period of time leading operational problems well after the fire that produced the smoke had been forgotten.

\section{THE FUTURE OF NUCLEAR POWER}

Nuclear power as it is known today is very likely to remain an important component of the nation's electrical power generation capability through at least to the year 2035. Is there a future of nuclear power beyond that is a question that probably cannot be answered. If there are to be new nuclear power plants in the USA, it will be because the plants can produce electricity at thermal to electrical conversion efficiencies much higher than what is possible today. Estimates have been that the thermal to electrical efficiency of a nuclear power plant would have to be on the order of $40 \%$ or more to be competitive with alternative power systems. To achieve such high efficiencies, a nuclear power plant would have to operate at much higher temperatures than they do today. Some estimate that the operating temperatures will have to be on the order of $1000 \mathrm{~K}$. The limitation on designing power generation systems that operate at such high temperatures for lifetimes of 40 years or more are, of course, materials limitations. I have every confidence that materials and material sciences will play a continuing important role in the nuclear power industry for the future. 


\section{REFERENCES}

1. R.O. Meyer, R.K. McCardell, H.M. Chung, D.J. Diamond, and H.H. Scott, Nuclear Safety 37, 271 (1996).

2. W. Marshall, An Assessment of the Integrity of PWR Pressure Vessels, United Kingdom Atomic Energy Authority, October, 1976

3. A. Brückner-Foit, Th. Schmidt, and J. Theodoropoulos, Nuclear Engineering and Design 110,395 (1989.

4. B. Chexal, J. Horowitz, R. Jones, B. Dooley, C. Wood, M. Bouchacourt, F. Ramy, F. Nordmann, and P. St. Paul, Flow-Accelerated Corrosion in Power Plants, TR-106611, Electric Power Research Institute, Palo Alto, CA, no date.

5. Y. M Ferng, Y.P. Ma, K.T. Ma, and N.M. Chung, Corrosion 55, 332 (1999).

6. T. J. Tanaka, Effects of Smoke on Functional Circuits, NUREG/CR-6543, SAND972544, Sandia National Laboratories, Albuquerque, NM, 1997. 


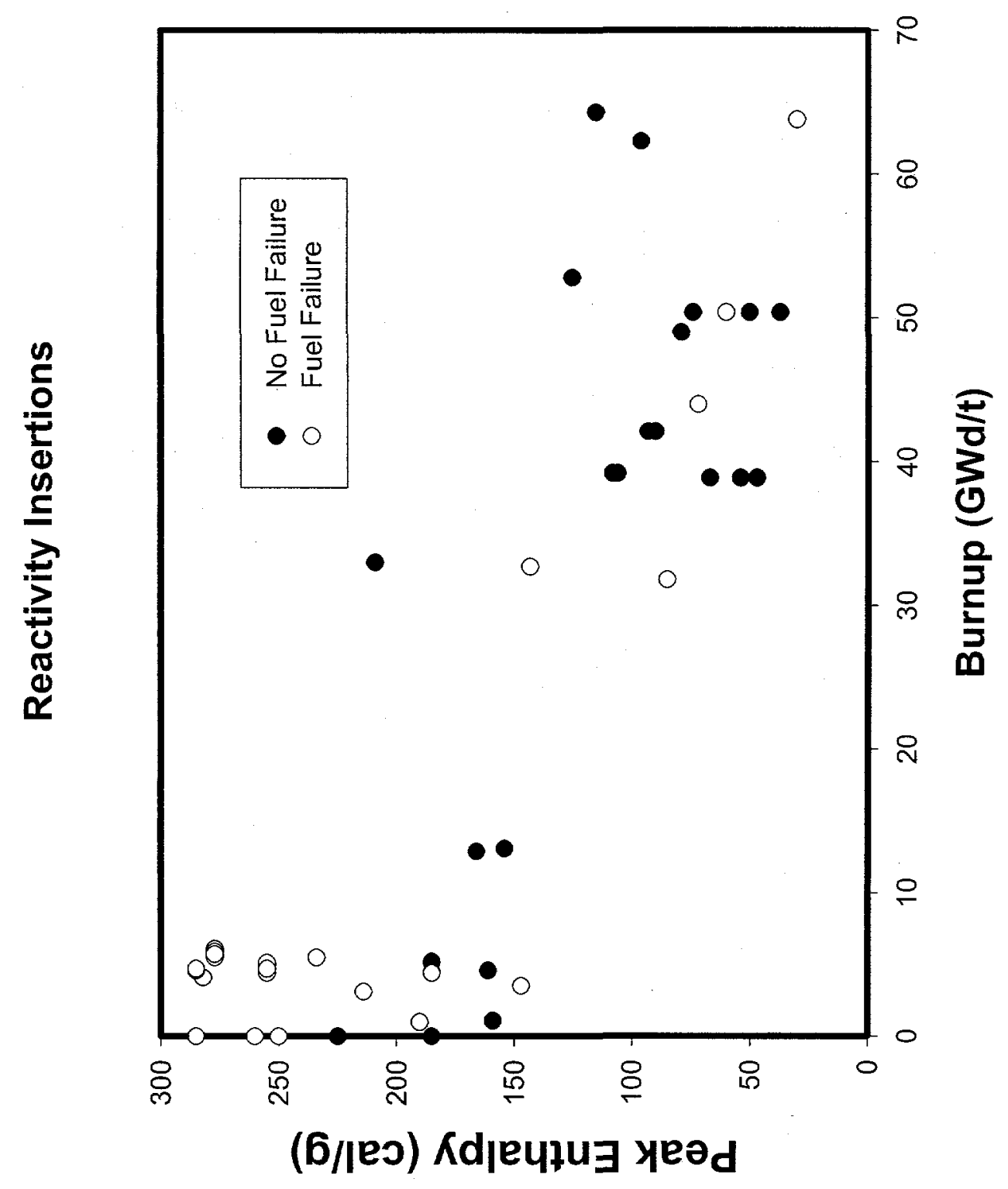

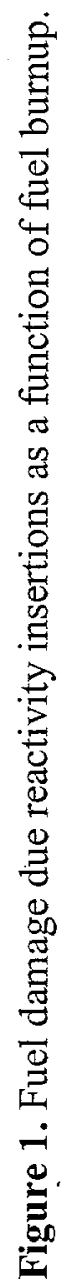




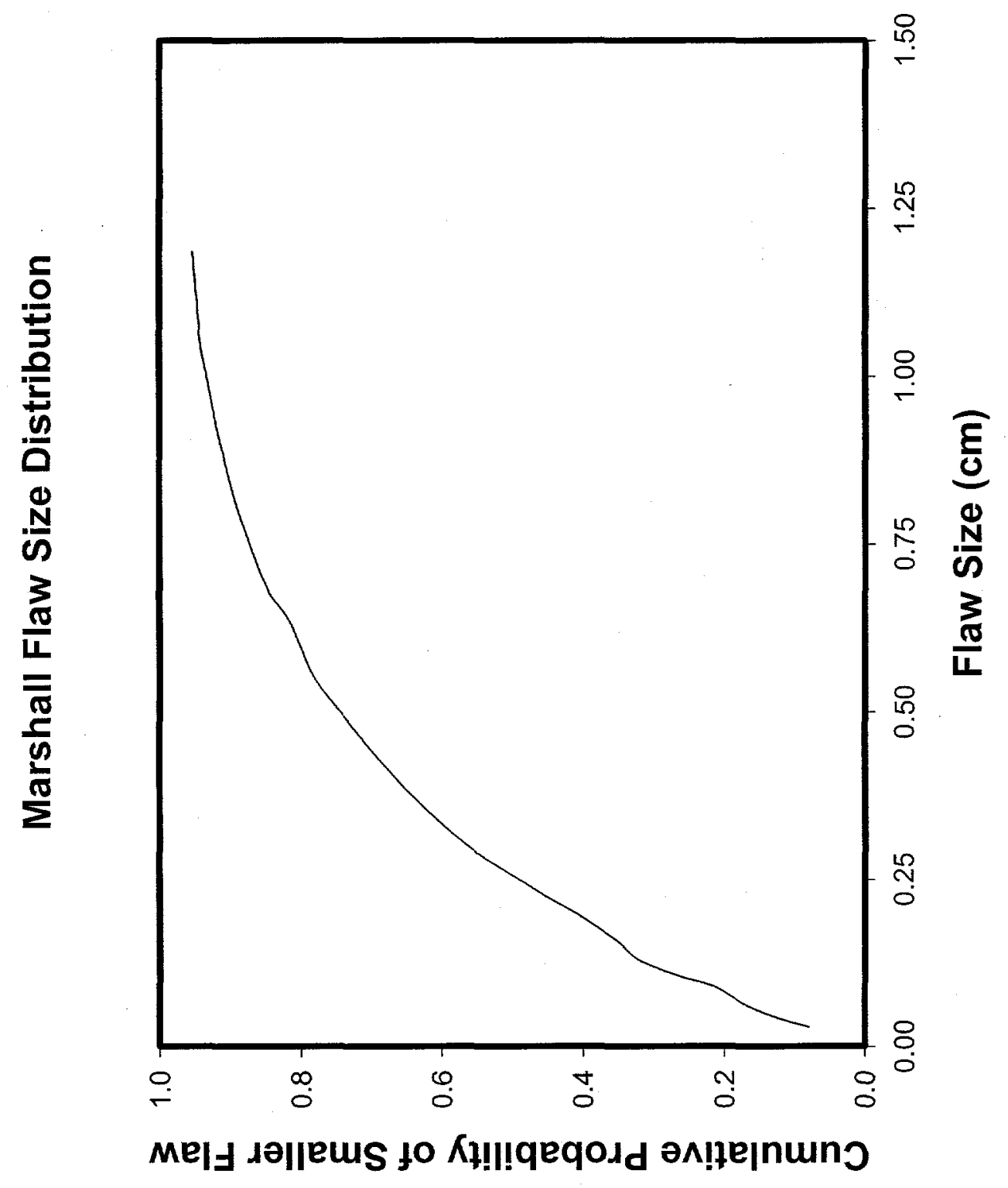

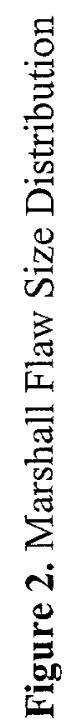

